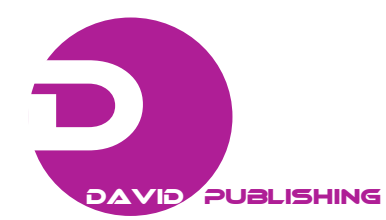

\title{
Effects of Sodium Metabisulfit and Ethylene Resin Wrapping on Browning of Young Shaped-Coconut
}

\author{
Ravy Por*, Borarin Buntong, Sopheap Ek, Kongkruy Chay and Vouchsim Kong \\ Royal University of Agriculture, P.O. Box 2696, Phnom Penh, Cambodia \\ *Corresponding authors email: ravy_rua@yahoo.com
}

\begin{abstract}
This study was conducted (i) to improve storage systems of young shaped-coconut before delivering to markets; (ii) to identify optimal concentration of sodium metabisulfit on young shaped-coconut; and (iii) to introduce suitable packaging preventing browning on young shaped-coconut. The experiment was replicated three times with two factors (the concentration of sodium metabisufit and packaging). Young shaped-coconuts were dipped in sodium metabisulfit (2\%, 5\%) for 2 min before wrapping (MAP) with polyethylene resin (PE Resin) or non-wrap to serve as control. Fruits were evaluated for shelf life, color changes (browning) and quality changes by using of 5-point Hedonic scale, while the data was recorded daily and analyzed of variances using IRRISTART program and Microsoft Excel. The results had shown that there were no significant differences of color changes (browning) on young shaped-coconuts with wrapping (MAP) or unwrapping $(P>0.05)$. Fruits washing with sodium metabisulfit was effectively reduced the color changes $(P<0.01)$ during the storage life. However, there was no significant difference between the concentration of sodium metabisulfit used $(P>0.05)$. In addition, fruits treated with sodium metabisulfit ( $2 \%, 5 \%)$ with wrapping extended the storage life up to 11 days, if compared to unwashed fruits that could store only 2 days. Fruits unwrapped and washed with sodium metabisulfit (2\%, 5\%) could be stored only 8 days. Moreover, wrapped fruits had the lowest percentage of weight losses and shriveling; whereas, $\mathrm{pH}$, sugar, and titratable acidity slowly decreased coconuts' water quality in all treatments.
\end{abstract}

Key words: Quality, sodium metabisulfit, wrapping, polyethylene resin. 